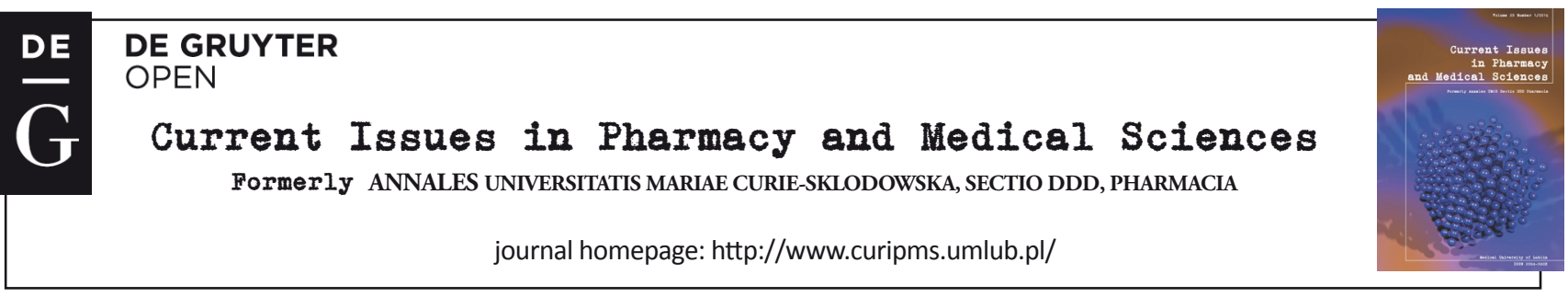

\title{
The fluctuation of free amino acids in serum during acute ischemic stroke
}

\author{
Maria SzPetnaR ${ }^{1}$, Anna Hordyjewska ${ }^{1}$, Iwona Malinowska ${ }^{2}$, \\ Piotr Golab ${ }^{3}$, JaceK KurzePA ${ }^{1 *}$
}

${ }^{1}$ Department of Medical Chemistry, Medical University of Lublin, Chodzki 4a, 20-093 Lublin, Poland

${ }^{2}$ Department of Mathematics, Lublin University of Technology, Lublin, Poland

${ }^{3}$ Department of Internal Medicine, The Holy Family Specialist Hospital in Rudna Mala, Poland

\begin{tabular}{l}
\hline ARTICLE INFO \\
\hline Received 24 March 2016 \\
Accepted 18 July 2016
\end{tabular}

Keywords:

amino acids,

biomarker,

ischemic stroke.

\begin{abstract}
Currently, little data exists regarding the involvement of free amino acids (AA) in the pathogenesis of ischemic stroke (IS). Thus, our objective was to study the degree of the degree of fluctuation of free amino acids level in serum during the acute phase of IS. The study consisted of eighteen patients (female/male: 10/8; age: $73.1 \pm 4.1$ ) with acute IS that was confirmed by way of computed tomography, while twelve sex and age matched individuals were assigned as control group. During the study period, the patients did not receive any supplemental amino acids therapy that could affect the obtained results. The venous blood was obtained after $>3$ hours fasting at two time-points; time-point $1-$ at admission to the hospital; time-point 2 - on day 5 from stroke onset. The blood for control purposes was collected only once, and the blood collection at time-point 1 was done before thrombolytic treatment (nine patients). The amino acids were identified using the Amino Acids Analyser (AAA 400) by INGOS Corp., Praha, Czech Republic. Our results revealed a statistically significant increase of glutamate, cystine and methionine on day 1 of stroke, in comparison to control, whereas, proline level was decreased on day 1 of stroke - in comparison to control serum. On comparing day 5 to the initial day of IS, elevation was observed of levels of asparagine, glycine, tyrosine, arginine, threonine, valine, leucine and phenylalanine. It can be said, then, that ischemic stroke induces both essential and nonessential amino acid fluctuations. Moreover, the decrease in proline and glutamine serum level with the simultaneous increase in the concentration of branch chain amino acids, Glu and Thr suggests a violent mobilization of the body's proteins. Thus, a decrease of Pro and a simultaneous increase of Glu serum level could be considered as a marker of acute IS.
\end{abstract}

\section{INTRODUCTION}

Worldwide, ischemic stroke (IS) is one of the leading causes of death and disability [8]. Contrary to other diseases, e.g. heart failure, the use of biomarkers for stroke detection is not accepted for routine application [14], and only head imaging, together with neurological assessment, gives a reliable diagnosis of stroke [10]. However, research of the fluctuation of various biochemical agents during acute IS (AIS) is needed for two main purposes: first, to help understand the biochemical changes that occur during the stroke, and, secondly, to discover a sensitive and specific indicator

\footnotetext{
* Corresponding author

e-mail: kurzepa@yahoo.com

phone: +48 814486190 , fax: + 48814486190
}

similar to brain imaging that can be used in clinical practice for diagnosis of stroke.

Currently, little data exists regarding fluctuation of free amino acids (AA) and their involvement in the pathogenesis of IS. Still, it is known that the plasma levels of excitatory AA such as glutamate (Glu) increase during AIS. Moreover, the Glu serum level measured within the first 6 hours of IS positively correlates with the ischemic focus volume [2]. However, thrombolytic therapy applied for AIS treatment has led to an early decrease in the Glu level, simultaneously with an increase in the level of neuroprotective $\gamma$-aminobutyric acid (GABA) [9]. Furthermore, the study performed by Kimberly et al. reveals a decrease in branched chain amino acids (BCAA), leucine (Leu), isoleucine (Ile), 
and valine (Val) after large infarction due to cardioembolic stroke [7]. In addition, one recent study in Japan has demonstrated that a dietary intake of glutamic acid and glycine may be associated with a higher risk of stroke mortality. This suggests they play a role in the IS pathogenesis [11]. However, currently there is no reliable evidence suggesting the possibility of using AA as the markers of stroke. Our objective, therefore, was to study the fluctuations of the free amino acid level in the serum of patients during the acute phase of IS.

\section{MATERIAL AND METHODS}

\section{Patients}

Eighteen patients with acute IS that was confirmed using the computed tomography (CT) were enrolled. Twelve sex and age matched individuals were assigned as control group. For IS patients, their neurological status was evaluated at admission via the use of the National Institutes of Health Stroke Scale (NIHSS). Nine of the study's IS patients were enrolled to $i v$. thrombolytic therapy with Actylise (Boehringer Ingelheim International, Ingelheim, Germany). During the study period, the patients did not receive supplemental amino acids therapy that could affect the obtained results. The characteristics of the study patients is given in Table 1. The local Ethics Committee (Medical University of Lublin) accepted the protocol of the study (agreement No. KE-0254/260/2013).

Table 1. Characteristic of study group

\begin{tabular}{|c|c|c|c|}
\hline & $\begin{array}{c}\text { Stroke patients } \\
n=18\end{array}$ & $\begin{array}{c}\text { Control } \\
\mathrm{n}=12\end{array}$ & $x^{2}$ \\
\hline Age (mean $\pm \mathrm{SD}$ ) & $73.1 \pm 4.1$ & $69.2 \pm 3.2$ & \multirow{7}{*}{$p>0.05$} \\
\hline Sex (male/female) & $10 / 8$ & $6 / 6$ & \\
\hline Hypertension (yes/no) & $13 / 5$ & $4 / 8$ & \\
\hline Diabetes (yes/no) & $3 / 15$ & $0 / 12$ & \\
\hline Coronary dis. (yes/no) & $13 / 5$ & $2 / 10$ & \\
\hline Atrial fibrillation (yes/no) & $5 / 13$ & $1 / 11$ & \\
\hline Smoking (yes/no) & $11 / 7$ & $7 / 5$ & \\
\hline  & $\begin{array}{l}1 \\
9 \\
6 \\
2\end{array}$ & & \\
\hline $\begin{array}{l}\text { NIHSS at the admission } \\
\text { (median, } 1^{\text {st }}-3^{\text {rd }} \text { quartile) }\end{array}$ & $12(7-19)$ & & \\
\hline $\begin{array}{l}\text { NIHSS at the discharge } \\
\text { (median, } 1^{\text {st- }} 3^{\text {rd }} \text { quartile) }\end{array}$ & $3(1-15.5)$ & & \\
\hline
\end{tabular}

\section{Sample collection}

The venous blood was obtained after $>3$ hours fasting at two time-points; time-point 1 - at their admission to the hospital; time-point 2 - on day 5 from stroke onset. The blood used for Control was collected only once. Time-point 1 covered the first $5 \pm 4$ hours of stroke (from "last seen well"). Because free arginine is the constituent of Actylise, the blood collection at time-point 1 was done before the application of thrombolytic treatment.

\section{AA analysis}

For amino acids analysis, serum samples were deproteinised with $6 \%$ sulphosalicylic acid in lithium-citrates buffer ( $\mathrm{pH} 2.8$ ), and centrifuged. AA were determined by way of automated ion-exchange chromatography, utilizing five lithium-citrate buffers, via the Amino Acids Analyser (AAA 400) by INGOS Corp., Praha, Czech Republic. The individual amino acids were separated using analytic column OSTION LG FA. The amino acids were identified through comparison to the standards provided by INGOS Corp. The original software MIKRO version 1.8.0 (INGOS, Praha, Czech Rep.) was employed for AA evaluation, and the amino acids serum level was expressed in $\mu \mathrm{M} / \mathrm{ml}$.

\section{Statistical analysis}

The presence of Gaussian distribution was estimated by way of the Lillefors test. The repeated measures analysis of variance (ANOVA) with Tukey-Kramer multiple comparisons post-hoc test or t-test were used for statistical analysis. A $p$-value $<0.05$ was considered statistically significant.

\section{RESULTS}

The fluctuation of essential and nonessential amino acids during the acute phase of IS is presented in Table 2. A statistically significant increase in Glu, cystine (cysteine is rapidly oxidized under physiological $\mathrm{pH}$ to cystine (Cyss)), and methionine (Met) was noticed on day 1 of stroke, in comparison to the control, whereas the proline (Pro) level

Table 2. The fluctuation of free amino acids in serum of stroke patients. CYSS - cystine; ANOVA with Tukey-Kramer post hoc test; arrows indicate the increase or decrease of amino acid serum level $v s$. control or day 1 respectively

\begin{tabular}{|c|c|c|c|c|c|}
\hline \multicolumn{6}{|c|}{ Non-essential amino acids } \\
\hline$A A$ & Control & Day 1 & vs Control & Day 5 & vs Day 1 \\
\hline ASN & $\begin{array}{l}0.03586 \pm \\
0.01\end{array}$ & $\begin{array}{l}0.03456 \pm \\
0.02256\end{array}$ & & $\begin{array}{l}0.05225 \pm \\
0.0276\end{array}$ & $\uparrow^{*}$ \\
\hline GLN & $\begin{array}{l}0.5742 \pm \\
0.1444\end{array}$ & $\begin{array}{l}0.4575 \pm \\
0.1934\end{array}$ & & $\begin{array}{l}0.3986 \pm \\
0.1524\end{array}$ & $\downarrow\left(^{*}\right)$ \\
\hline GLU & $\begin{array}{l}0.05986 \pm \\
0.0324\end{array}$ & $\begin{array}{l}0.1341 \pm \\
0.058\end{array}$ & $\uparrow \uparrow^{\star *}$ & $\begin{array}{l}0.1458 \pm \\
0.065\end{array}$ & $\uparrow\left(^{*}\right)$ \\
\hline GLY & $\begin{array}{l}0.2642 \pm \\
0.1049\end{array}$ & $\begin{array}{l}0.2492 \pm \\
0.08395\end{array}$ & & $\begin{array}{l}0.304 \pm \\
0.08395\end{array}$ & $\uparrow \uparrow^{* *}$ \\
\hline TYR & $\begin{array}{l}0.05514 \pm \\
0.01985\end{array}$ & $\begin{array}{l}0.06869 \pm \\
0.01985\end{array}$ & & $\begin{array}{l}0.08456 \pm \\
0.02068\end{array}$ & $\uparrow^{*}$ \\
\hline ARG & $\begin{array}{l}0.1202 \pm \\
0.02445\end{array}$ & $\begin{array}{l}0.1268 \pm \\
0.01356\end{array}$ & & $\begin{array}{l}0.15167 \pm \\
0.02347\end{array}$ & $\uparrow^{*}$ \\
\hline ASP & $\begin{array}{l}0.042 \pm \\
0.00858\end{array}$ & $\begin{array}{l}0.04314 \pm \\
0.0209\end{array}$ & & $\begin{array}{l}0.05338 \pm \\
0.01246\end{array}$ & \\
\hline SER & $\begin{array}{l}0.12243 \pm \\
0.01921\end{array}$ & $\begin{array}{l}0.1275 \pm \\
0.03586\end{array}$ & & $\begin{array}{l}0.1458 \pm \\
0.02621\end{array}$ & \\
\hline PRO & $\begin{array}{l}0.62314 \pm \\
0.1811\end{array}$ & $\begin{array}{l}0.27413 \pm \\
0.1502\end{array}$ & $\downarrow \downarrow \downarrow^{* \star *}$ & $\begin{array}{l}0.3198 \pm \\
0.17959\end{array}$ & \\
\hline ALA & $\begin{array}{l}0.468 \pm \\
0.06959\end{array}$ & $\begin{array}{l}0.3726 \pm \\
0.10336\end{array}$ & & $\begin{array}{l}0.40594 \pm \\
0.08693\end{array}$ & \\
\hline CYSS & $\begin{array}{l}0.00043 \pm \\
0.0007\end{array}$ & $\begin{array}{l}0.00656 \pm \\
0.01268\end{array}$ & $\uparrow^{*}$ & $\begin{array}{l}0.01181 \pm \\
0.01434\end{array}$ & \\
\hline HIS & $\begin{array}{l}0.06971 \pm \\
0.01137 \\
\end{array}$ & $\begin{array}{l}0.07919 \pm \\
0.01684 \\
\end{array}$ & & $\begin{array}{l}0.08 \pm \\
0.0171 \\
\end{array}$ & \\
\hline \multicolumn{6}{|c|}{ Essential amino acids } \\
\hline AA & Control & Day 1 & vs Control & Day 5 & vs Day 1 \\
\hline THR & $\begin{array}{l}0.13357 \pm \\
0.05247\end{array}$ & $\begin{array}{l}0.10275 \pm \\
0.01941\end{array}$ & & $\begin{array}{l}0.1574 \pm \\
0.03667\end{array}$ & $\uparrow \uparrow \uparrow * \star \star$ \\
\hline VAL & $\begin{array}{l}0.1814 \pm \\
0.03787\end{array}$ & $\begin{array}{l}0.22069 \pm \\
0.056\end{array}$ & & $\begin{array}{l}0.29188 \pm \\
0.07806\end{array}$ & $\uparrow \uparrow^{\star *}$ \\
\hline LEU & $\begin{array}{l}0.097 \pm \\
0.0224 \\
\end{array}$ & $\begin{array}{l}0.1295 \pm \\
0.05241\end{array}$ & & $\begin{array}{l}0.1745 \pm \\
0.06735\end{array}$ & $\uparrow^{*}$ \\
\hline PHE & $\begin{array}{l}0.04571 \pm \\
0.0077\end{array}$ & $\begin{array}{l}0.0625 \pm \\
0.01394\end{array}$ & & $\begin{array}{l}0.08181 \pm \\
0.02047\end{array}$ & $\uparrow \uparrow^{\star *}$ \\
\hline MET & $\begin{array}{l}0.01429 \pm \\
0.00854\end{array}$ & $\begin{array}{l}0.02788 \pm \\
0.01518\end{array}$ & $\uparrow^{*}$ & $\begin{array}{l}0.02956 \pm \\
0.01316\end{array}$ & \\
\hline ILE & $\begin{array}{l}0.04071 \pm \\
0.01426\end{array}$ & $\begin{array}{l}0.0535 \pm \\
0.02645\end{array}$ & & $\begin{array}{l}0.06963 \pm \\
0.03408\end{array}$ & \\
\hline TRP & $\begin{array}{l}0.06314 \pm \\
0.01549\end{array}$ & $\begin{array}{l}0.06506 \pm \\
0.02946\end{array}$ & & $\begin{array}{l}0.07444 \pm \\
0.02404\end{array}$ & \\
\hline LYS & $\begin{array}{l}0.1701 \pm \\
0.037\end{array}$ & $\begin{array}{l}0.26156 \pm \\
0.1599\end{array}$ & & $\begin{array}{l}0.23869 \pm \\
0.05152\end{array}$ & \\
\hline
\end{tabular}


was decreased on day 1 of stroke, in comparison to the control serum. On comparing day 5 to the initial day of IS, elevation of the asparagine (Asn), glycine (Gly), tyrosine (Tyr), arginine (Arg), threonine (Thr), Val, Leu and phenylalanine (Phe) levels was observed. Still, the increase in Glu and the decrease in glutamine (Gln) serum levels did not reach statistical significance $(\mathrm{p}<0.1)$.

\section{DISCUSSION}

Besides their role in peptide and protein synthesis, free AA are precursors of several biologically active compounds (e.g. taurine, heme, nitrogenous bases) and hormones (epinephrine, norepinephrine, dopamine, thyroid hormones) [23]. In addition, AA can regulate gene expression at transcriptional [1], translational, and post-translational levels [5].

Furthermore, an elevated AA level (e.g. after intravenous administration) can stimulate the secretion of hormones from the endocrine cells [12] and affect hormonal homeostasis. What is more, after the administration of Arg, secretions of insulin, growth hormone, prolactin, glucagon and progesterone are increased [24].

The AA plasma level is relatively constant in healthy adults. However, in several diseases, circulating AA undergo dynamic changes [23], yet, data relating to the fluctuation of the amino acid level in serum during IS are elusive. A previous study has revealed a decrease in BCAA (which are essential amino acids) in the course of acute cardioembolic stroke [7]. Moreover, our preceding study revealed an early decrease in the BCAA plasma level measured in patients after myocardial infarction (MI). In this study, the BCAA level was restored to the values noticed in control patients on day 5 after MI [18]. Still, it was recognized that the serum level of BCAA in patients with stable coronary heart disease (CHD) is decreased in comparison to healthy controls [18]. Furthermore, a current study has shown that Leu, Val, and Ile measured at time-point 1 did not significantly differ in comparison to the control; however, the Leu and Val level was elevated on day 5 , compared to time-point 1 . The elevation of plasma BCAA was previously noticed in individuals after 3 days of fasting, in parallel with increased protein degradation [20]. Therefore, the observed rise in the BCAA level either can indicate the nutritional state of stroke patients or can be the cause of intense metabolic processes due to increased activity of proinflammatory cytokines. In addition, the elevation of the Phe and Tyr serum level after stroke can be generated by the competitive transport of BCAA and aromatic AA into the central nervous system, subsequently leading to disturbances in the synthesis of catecholamines thereafter [21].

In our work, a significant 2-fold decrease in Pro and a 2-fold increase in Glu were observed on day 1, in comparison to the control samples. This suggests that changes in Pro and Glu could be considered as a marker of AIS in future research. As mentioned above, it is known that Glu increases early in plasma during AIS [2]. Pro plays an important role in the stimulation of glutaminergic neurons, and Pro has been proposed as being a neuromodulator and neurotransmitter in the central nervous system [19]. It is synthesized mostly from Gln in vivo [6]; therefore, the observed decrease in Pro could have been brought about by the Gln decrease (insignificant in our research). Pro deficiency is known to impair collagen synthesis [13], which may be significant during the ischemia repairing processes. What is more, former research has shown that the serum level of a majority of the analyzed amino acids, except Gln $(p<0.1)$, rises in the progress of stroke. In our work, the trend towards the decrease in Gln on day 5 of stroke could have been induced by its degradation to Glu and ammonia, resulting in an increase in the Glu serum level. In addition, the observed elevation of Glu in IS patients vs. controls could have been caused by its release from damaged neurons, leading to excitotoxicity - an important factor for the neuronal cell death during brain ischemia [9]. However, the higher Glu serum level (after iv. AA administration) was seen to result in an increase in insulin secretion [12,24], which could have reduced hyperglycemia and might potentially improve the stroke outcome [17].

It should be noted that half of the study patients received thrombolytic therapy with rtPA. To improve the solubility of rtPA, L-arginine is added into the drug as its constituent, and patients during thrombolysis received approximately $3.0 \mathrm{~g}$ of L-arginine [3]. The previous study revealed an increase in the Arg serum level directly after the thrombolysis, but on day 5 of stroke, the Arg level was restored to the level noticed in IS patients without thrombolytic therapy [4].

AA are generally stable at the physiological solution. However, cysteine is rapidly oxidized to cystine [23]. Therefore, cystine was found in the serum of both the study and control patients. The mean cystine level was dramatically (but statistically insignificantly) increased in the serum on day 5 of stroke. However, the increase in Cyss on day $1 v s$. controls is consistent with other research [15]. Cysteine is known to promote neuronal cell death and was reported to be elevated in brain ischemia. Raised cystine (and cysteine) in the serum of patients with ischemic stroke may, therefore, indicate increased production of $\mathrm{H}_{2} \mathrm{~S}$ in the brain, resulting in poor outcome [22]. The experimental study showed that a methionine metabolite homocysteine induces the death of glial cells. This observation suggests involvement of homocysteine in neurodegeneration [16].

\section{CONCLUSIONS}

Ischemic stroke brings about both essential and nonessential amino acid fluctuations. This suggests the violent mobilization of the body's proteins. Furthermore, the decrease of Pro and increase of Glu serum level could be considered as being a marker of acute IS.

\section{CONFLICT OF INTERESTS}

The authors do not declare a conflict of interests.

\section{REFERENCES}

1. Brasse-Lagnel C. et al.: Glutamine stimulates argininosuccinate synthetase gene expression through cytosolic O-glycosylation of Sp1 in Caco-2 cells. J Biol Chem., 278, 52504, 2003. 
2. Castillo J., Rodriguez I.: Biochemical changes and inflammatory response as markers for brain ischaemia: molecular markers of diagnostic utility and prognosis in human clinical practice. Cerebrovasc Dis., 17 Suppl 1, 7, 2004.

3. Harston, George W J et al.: The contribution of L-arginine to the neurotoxicity of recombinant tissue plasminogen activator following cerebral ischemia: a review of rtPA neurotoxicity. J Cereb Blood Flow Metab., 30, 1804, 2010.

4. Horecka A. et al.: Actylise treatment does not influence nitric oxide metabolites serum level. Pharmacol Rep, 2016.

5. Huang Y.F., Wang Y., Watford M.: Glutamine directly downregulates glutamine synthetase protein levels in mouse $\mathrm{C} 2 \mathrm{C} 12$ skeletal muscle myotubes. J Nutr., 137, 1357, 2007.

6. Karna E., Szoka L., Palka J.A.: Captopril-dependent inhibition of collagen biosynthesis in cultured fibroblasts. Pharmazie., 65, 614, 2010.

7. Kimberly W.T. et al.: Metabolite profiling identifies a branched chain amino acid signature in acute cardioembolic stroke. Stroke., 44, 1389, 2013.

8. Kuklina E.V. et al.: Epidemiology and prevention of stroke: a worldwide perspective. Expert Rev Neurother., 12, 199, 2012.

9. Kurzepa J. et al.: Thrombolytic treatment decreases glutamate/GABA ratio in serum during acute ischaemic stroke: a pilot study. Neurol Res., 37, 934, 2015.

10. Miao Y., Liao J.K.: Potential serum biomarkers in the pathophysiological processes of stroke. Expert Rev Neurother., 14, 173, 2014.

11. Nagata C. et al.: Dietary intakes of glutamic Acid and glycine are associated with stroke mortality in Japanese adults. J Nutr., 145, 720, 2015.

12. Newsholme P. et al.: New insights into amino acid metabolism, betacell function and diabetes. Clin Sci (Lond)., 108, 185, 2005.

13. Phang J.M. et al.: Proline metabolism and cancer: emerging links to glutamine and collagen. Curr Opin Clin Nutr Metab Care., 18, $71,2015$.
14. Raman K., Pare G.: Of stroke and biomarkers: the elusive quest for a clinical biomarker panel. Clin Biochem., 46, 705, 2013.

15. Salemi G. et al.: Blood levels of homocysteine, cysteine, glutathione, folic acid, and vitamin B12 in the acute phase of atherothrombotic stroke. Neurol Sci., 30, 361, 2009.

16. Skovierova H. et al.: Effect of homocysteine on survival of human glial cells. Physiol Res, 2015.

17. Staszewski J. et al.: Intravenous insulin therapy in the maintenance of strict glycemic control in nondiabetic acute stroke patients with mild hyperglycemia. J Stroke Cerebrovasc Dis., 20, 150, 2011.

18. Szpetnar M., Pasternak K., Boguszewska A.: Branched chain amino acids (BCAAs) in heart diseases (ischaemic heart disease and myocardial infarction). Ann Univ Mariae Curie Sklodowska Med., 59, 91, 2004.

19. Takemoto Y.: Intracisternally injected L-proline activates hypothalamic supraoptic, but not paraventricular, vasopressinexpressing neurons in conscious rats. J Amino Acids., 2011, 230613, 2011.

20. Tom A., Nair K.S.: Assessment of branched-chain amino Acid status and potential for biomarkers. J Nutr., 136, 324S-30S, 2006.

21. Watford M.: Lowered concentrations of branched-chain amino acids result in impaired growth and neurological problems: insights from a branched-chain alpha-keto acid dehydrogenase complex kinasedeficient mouse model. Nutr Rev., 65, 167, 2007.

22. Wong, Peter T H et al.: High plasma cyst(e)ine level may indicate poor clinical outcome in patients with acute stroke: possible involvement of hydrogen sulfide. J Neuropathol Exp Neurol., 65, 109, 2006.

23. Wu G.: Amino acids: metabolism, functions, and nutrition. Amino Acids., 37, 1, 2009.

24. Wu G. et al.: Arginine metabolism and nutrition in growth, health and disease. Amino Acids., 37, 153, 2009. 